Published in final edited form as:

J Urol. 2008 December ; 180(6): 2565-2568. doi:10.1016/j.juro.2008.08.042.

\title{
Vasectomy and Risk of Prostate Cancer
}

\author{
Sarah K. Holt ${ }^{1}$, Claudia A. Salinas ${ }^{1,2}$, and Janet L. Stanford ${ }^{1,2}$ \\ 1 Division of Public Health Sciences, Fred Hutchinson Cancer Research Center, Seattle, WA
}

2 Department of Epidemiology, University of Washington, Seattle, WA

\section{Abstract}

Purpose-While the weight of evidence shows no association overall between vasectomy and prostate cancer, there has been some suggestion that an association may exist in subgroups such as men who have a family history of prostate cancer, men who undergo vasectomy at younger ages, or when several decades have passed since the procedure. Studies examining risk with long latency periods have been hampered by small sample sizes within subgroups since vasectomy only became widely used in the 1960s and generally, prostate cancer has a long latency period.

Materials and Methods-We analyzed data from a recent population-based case-control study that was designed specifically to address this issue of risk within subgroups. Interviews were completed for 1,001 men diagnosed with prostate cancer from January 1, 2002 through December 31, 2005 in the Seattle-Puget Sound Region and 942 matched control men. Subjects were AfricanAmerican and Caucasian men between the ages of 35 and 74 . Data were analyzed using unconditional logistic regression to calculate odds ratios as estimates of the relative risk of prostate cancer associated with various parameters of vasectomy.

Results - The prevalence of vasectomy was similar in the cases (36.2\%) and controls (36.1\%) with an adjusted odds ratio of 1.0 (95\% CI 0.8-1.2). There were also no associations observed between prostate cancer and age at vasectomy, years elapsed since vasectomy, or calendar year of vasectomy.

Conclusions-These findings indicate there is no association between vasectomy and risk of prostate cancer.

\section{Keywords}

Prostatic Neoplasms; Case-Control Studies; Vasectomy

\section{Introduction}

Early studies examining the risk of prostate cancer for men undergoing vasectomy had inconsistent results and methodological issues including control selection, potential detection bias, and potential misclassification bias ${ }^{1,2}$. Initial positive associations reported in the early 1990's were followed by a number of studies which carefully addressed concerns with study designs and subsequently did not confirm the findings ${ }^{3-7}$. These later studies, however, were limited by the short time intervals between exposure and disease since vasectomy only became widely used in the 1960s and generally, prostate cancer has a long latency period. To address this issue, we analyzed data from a recent case-control study to assess risk of prostate cancer in a birth cohort with higher exposure and longer latency periods between exposure and disease.

\section{Material and Methods}

This was a population-based prostate cancer case-control study of Caucasian and African American men aged 35 to 74 years residing in King County, Washington ${ }^{8}$. Cases with 
histologically confirmed prostate cancer from January 1, 2002 through December 31, 2005 were identified from the SEER Seattle-Puget Sound tumor registry. Of the 1,327 men eligible for the study, 1,001 completed structured in-person interviews (75.0\%). Eligible controls were identified through random digit telephone dialing (RDD) and frequency matched to cases by 5 -year age group. Complete household census information was obtained for $81.4 \%$ of residential telephone numbers contacted. Of the 1,340 eligible men who were identified and agreed to receive information about the study, 942 (70.3\%) were interviewed. Both cases and controls completed detailed in-person interviews covering demographic, medical, and family cancer history conducted by trained male interviewers. This study was approved by Fred Hutchinson Cancer Research Center's Institutional Review Board.

Data were analyzed using unconditional logistic regression to calculate odds ratios as estimates of the relative risk of prostate cancer associated with various parameters of vasectomy. Subset analysis by tumor stage (local vs. regional/distant), Gleason score $[\leq 7(3+4)$ vs. $\geq 7(4+3)]$, and a composite prostate cancer aggressiveness score was conducted using polytomous regression. Polytomous regression is a more accurate method of estimating risk and variance of such estimates when comparing multiple case groups simultaneously with a group of controls. These analyses, where the stratified cases (e.g., high/low Gleason score) were compared to controls within one model, allows for direct testing of differences in risk estimates among case groups and yields more accurate variance estimates for calculation of confidence intervals. This approach is preferable to running separate logistic regression models for the various case groups compared to the same group of controls as the latter methods does not provide the most valid estimates of variance and does not provide the opportunity to test for difference in risk estimates between case groups." Classification parameters of the composite "less aggressive" phenotype included local stage, Gleason score $\leq 7(3+4)$, and serum PSA $<20 \mathrm{ng} / \mathrm{ml}$, whereas the "more aggressive" phenotype included regional/distant stage, or Gleason score $\geq 7(4+3)$, or serum PSA $\geq 20 \mathrm{ng} / \mathrm{ml}$. Established and suspected prostate cancer risk factors were examined for potential confounding effects. We included age, race, first-degree family history of prostate cancer and screening history (PSA/DRE within the past 5 years) in all models. Trend tests of risk estimates were analyzed by examining vasectomy parameters as continuous variables. Multiplicative effect modification was evaluated using likelihood ratio tests. Analyses were also done excluding subjects according to factors that may be associated with detection bias, such as undiagnosed prostate cancer in the control group or a short latency period between the diagnosis and vasectomy dates. All analyses were done using STATA (version 9.2, STATA Corp., College Station, TX).

\section{Results}

The distribution of potential risk factors in the case versus controls mirrors that of other population based studies (data not shown) 7,9 . Cases were more likely to be African American, have a first degree relative with prostate cancer, and have undergone PSA or DRE screening in the 5 years prior to the study reference date. The distribution of potential risk factors for prostate cancer and vasectomy status in the controls showed that men who had a vasectomy were more likely to be older, Caucasian, married, nonsmokers, regular consumers of alcohol, have a higher income and education, and have undergone PSA screening (Table 1). Overall, $36 \%$ of cases and controls had undergone a vasectomy. No associations were observed between prostate cancer and vasectomy status, age at vasectomy, years elapsed since vasectomy, or calendar year of vasectomy (Table 2). The mean number of years since vasectomy was 21.1 in both cases and controls. There was no evidence of a trend in risk estimates across any of the vasectomy parameters. There was no suggestion of effect modification by age, race, family history or history of BPH. Further, polytomous regression risk estimates did not vary by clinical parameters (data not shown). Lastly, there was no substantial change in risk estimates for 
analyses excluding controls who has not received a PSA or DRE in the last five years ( $\mathrm{n}=136)$ or cases that were diagnosed with prostate cancer within 2 years of their vasectomy date $(n=8)$.

\section{Discussion}

This population-based case-control study did not find any evidence of an association with vasectomy. In both the cases and the non-diseased control population we had a prevalence of $36 \%$ for men reporting a vasectomy. We believe that our data are a true reflection of vasectomy prevalence in this population. The 2002 data taken from the Behavioral Risk Factor Survey Study (BRFSS) shows $29.8 \%$ of men over the age of 18 in Washington state report vasectomy as their primary means of birth control ${ }^{10}$. In addition, we reported $37.7 \%$ of the controls as having a vasectomy in our previous case-control study done from 1993-1996 that was limited to ages $40-64^{6}$. When we looked within this age group for the current case-control study we observed a $34.4 \%$ prevalence of vasectomy in the controls.

We had a large enough study population to fully explore potential associations within subgroups and were able to carefully evaluate detection bias. Only $14.4 \%$ of the controls had no history of PSA or DRE screening in the past 5 years. Thus, the likelihood of misclassification bias is small given the fact that our risk estimates did not change after these men were excluded. We used self-reported vasectomy data, which could involve bias in exposure measurement; however our earlier study showed $100 \%$ reliability of self-reported vs. medical records data on vasectomy 6 .

A recent meta-analysis, which included our 1999 study and eight other population-based casecontrol studies, reported an overall odds ratio of 1.1 (95\% CI, 0.9-1.4) for the risk of prostate cancer with vasectomy ${ }^{1}$. While the weight of evidence shows no association overall, there has been some suggestion that an association may exist in subgroups such as men who have a family history of prostate cancer, men who undergo vasectomy at younger ages, or when several decades have passed since the procedure ${ }^{11,12}$. A recent well-designed study out of New Zealand, where vasectomy is the most prevalent in the world, did not report any association in these subgroups ${ }^{9}$. Our study also did not find any evidence of an association by age at vasectomy, family history of disease, or by latency periods between exposure and disease.

\section{Conclusion}

This study was specifically designed to address the question of whether or not vasectomy is a risk for prostate cancer. We had the advantage of utilizing data from a birth cohort with high exposure and longer latency periods between exposure and disease. These findings indicate there is no association between vasectomy and risk of prostate cancer. In addition, we did not find evidence of increased risk of prostate cancer in younger men who had undergone vasectomy or in men with extended periods of time since undergoing the procedure.

\section{Acknowledgements}

FINANCIAL SUPPORT: This work was supported by grants CA92579 and CA97186, and contract NO1-PC-35142 from the National Cancer Institute; additional support was provided by the Fred Hutchinson Cancer Research Center.

\section{Reference List}

1. Dennis LK, Dawson DV, Resnick MI. Vasectomy and the Risk of Prostate Cancer: a Meta-Analysis Examining Vasectomy Status, Age at Vasectomy, and Time Since Vasectomy. Prostate Cancer \& Prostatic Dis 2002;5:193. 
2. Bernal-Delgado E, Latour-Perez J, Pradas-Arnal F, Gomez-Lopez LI. The Association Between Vasectomy and Prostate Cancer: a Systematic Review of the Literature. Fertil Steril 1998;70:191. [PubMed: 9696205]

3. Rosenberg L, Palmer JR, Zauber AG, Warshauer ME, Stolley PD, Shapiro S. Vasectomy and the Risk of Prostate Cancer. Am J Epidemiol 1990;132:1051. [PubMed: 2260536]

4. Mettlin C, Natarajan N, Huben R. Vasectomy and Prostate Cancer Risk. Am J Epidemiol 1990;132:1056. [PubMed: 2260537]

5. Spitz MR, Fueger JJ, Babaian RJ, Newell GR. Re: Vasectomy and the risk of prostate cancer. Am J Epidemiol 1991;134:107. [PubMed: 1853855]

6. Stanford JL, Wicklund KG, McKnight B, Daling JR, Brawer MK. Vasectomy and risk of prostate cancer. Cancer Epidemiol Biomarkers Prev 1999;8:881. [PubMed: 10548316]

7. Lesko SM, Louik C, Vezina R, Rosenberg L, Shapiro S. Vasectomy and Prostate Cancer. J Urol 1999;161:1848. [PubMed: 10332451]

8. Agalliu I, Salinas CA, Hansten PD, Stanford JL. Statin use and prostate cancer risk: a population-based case-control study. Am J Epidemiol. 2008In Press

9. Cox B, Sneyd MJ, Paul C, Delahunt B, Skegg DCG. Vasectomy and risk of prostate cancer. JAMA 2002;287:3110. [PubMed: 12069674]

10. Bensyl DM, Iuliano D, Carter M, Santelli J, Gilbert BC. Contraceptive Use - United States and Territories, Behavioral Risk Factor Surveillance System, 2002. MMWR 2008;54:1-72. [PubMed: 16292246]

11. Zhu K, Stanford JL, Daling JR, McKnight B, Stergachis A, Brawer MK, et al. Vasectomy and Prostate Cancer: a Case-Control Study in a Health Maintenance Organization. Am J Epidemiol 1996;144:717. [PubMed: 8857819]

12. Giovannucci E. Medical History and Etiology of Prostate Cancer. Epidemiologic Reviews 2001;23:159. [PubMed: 11588842] 
Table 1

Distribution of potential confounders (\%) among control men with and without vasectomy, King Country, Washington, 2002-2005

\begin{tabular}{|c|c|c|}
\hline & Controls with vasectomy(n=340) & Controls without vasectomy $(n=602)$ \\
\hline \multicolumn{3}{|l|}{ Age at reference date (yrs) } \\
\hline $40-49$ & 7.9 & 11.5 \\
\hline $50-54$ & 9.4 & 13.5 \\
\hline $55-59$ & 19.1 & 18.1 \\
\hline $60-64$ & 21.2 & 19.1 \\
\hline $65-69$ & 23.8 & 20.1 \\
\hline $70-74$ & 18.5 & 17.8 \\
\hline \multicolumn{3}{|l|}{ Race } \\
\hline Caucasion & 94.7 & 86.7 \\
\hline African American & 5.3 & 13.3 \\
\hline \multicolumn{3}{|l|}{ First-degree relative with prostate cancer } \\
\hline Yes & 10.9 & 12.0 \\
\hline \multicolumn{3}{|l|}{ Marital Status } \\
\hline Married or living as married & 91.2 & 75.7 \\
\hline Single & 0.6 & 9.5 \\
\hline Other & 8.2 & 14.8 \\
\hline \multicolumn{3}{|l|}{ Annual Income } \\
\hline$<\$ 30,000$ & 9.3 & 18.8 \\
\hline$\$ 30,000-49,999$ & 20.6 & 17.2 \\
\hline$\$ 50,000-74,999$ & 22.4 & 22.5 \\
\hline$\$ 75,000-99,999$ & 19.1 & 16.0 \\
\hline$\geq \$ 100,000$ & 28.7 & 25.6 \\
\hline \multicolumn{3}{|l|}{ Education level } \\
\hline High School or less & 16.2 & 20.9 \\
\hline Some College or Voc tech & 24.5 & 21.1 \\
\hline College Degree & 29.8 & 26.6 \\
\hline Graduate School & 29.5 & 31.4 \\
\hline \multicolumn{3}{|l|}{ History of $\mathrm{BPH}^{a}$} \\
\hline None & 75.3 & 79.1 \\
\hline Diagnosis $\leq 2$ yrs from reference & 2.7 & 3.4 \\
\hline \multicolumn{3}{|l|}{ date } \\
\hline Diagnosis $>2$ yrs from reference & 22.0 & 17.6 \\
\hline date & & \\
\hline \multicolumn{3}{|l|}{ Smoking status } \\
\hline Nonsmoker & 42.8 & 47.2 \\
\hline Former smoker & 47.2 & 38.9 \\
\hline Current smoker & 10.0 & 14.0 \\
\hline \multicolumn{3}{|c|}{ Regular consumer of alcoholic beverages $b$} \\
\hline Yes & 79.7 & 72.6 \\
\hline \multicolumn{3}{|l|}{ Religious preference } \\
\hline Catholic & 18.9 & 21.8 \\
\hline Jewish & 1.8 & 2.5 \\
\hline Protestant/Other & 79.4 & 75.7 \\
\hline \multicolumn{3}{|l|}{ History of DRE and PSA tests ${ }^{c}$} \\
\hline None & 10.3 & 16.8 \\
\hline DRE only & 28.5 & 27.6 \\
\hline PSA & 61.2 & 55.6 \\
\hline
\end{tabular}

${ }^{a}$ Benign prostatic hyperplasia diagnosed at specific time periods before reference date.

${ }^{b}$ Regular consumers had at least 1 drink/month for $\geq 6$ months.

${ }^{c}$ Tests performed within the 5 years before reference date. 
Table 2

Association of vasectomy with risk of prostate cancer, King County, Washington, 2002-2005

\begin{tabular}{|c|c|c|c|}
\hline Vasectomy Status & Cases $(\%)(\mathrm{n}=1001)$ & Controls $(\%)(\mathrm{n}=942)$ & Adjusted $\mathrm{OR}^{a}(95 \% \mathrm{CI})$ \\
\hline \multicolumn{4}{|l|}{ Ever } \\
\hline No & $639(63.8)$ & $602(63.9)$ & $1.0(\mathrm{ref})^{b}$ \\
\hline Yes & $362(36.2)$ & $340(36.1)$ & $1.0(0.8-1.2)$ \\
\hline \multicolumn{4}{|c|}{ Age at Vasectomy $(\mathrm{yrs})^{c}$} \\
\hline$<30$ & $67(18.6)$ & $62(18.2)$ & $1.0(0.7-1.5)$ \\
\hline $30-34$ & $82(22.7)$ & $93(27.4)$ & $0.8(0.6-1.2)$ \\
\hline $35-39$ & $94(26.0)$ & $96(28.2)$ & $0.9(0.7-1.3)$ \\
\hline \multirow[t]{2}{*}{$\geq 40$} & $118(32.7)$ & $89(26.2)$ & $1.3(0.9-1.7)$ \\
\hline & & trend test $d$ & $P=0.28$ \\
\hline \multicolumn{4}{|c|}{ Years since vasectomy ${ }^{c}$} \\
\hline$<15$ & $69(19.1)$ & $67(19.7)$ & $1.1(0.7-1.6)$ \\
\hline $15-19$ & $47(13.0)$ & $30(8.8)$ & $1.6(1.0-2.7)$ \\
\hline $20-24$ & $46(12.7)$ & $42(12.4)$ & $1.1(0.7-1.7)$ \\
\hline $25-29$ & $69(19.1)$ & $58(17.1)$ & $1.1(0.8-1.6)$ \\
\hline $30-34$ & $74(20.5)$ & $78(22.9)$ & $0.9(0.6-1.2)$ \\
\hline \multirow[t]{2}{*}{$\geq 35$} & $56(15.5)$ & $65(19.1)$ & $0.7(0.5-1.1)$ \\
\hline & & trend test ${ }^{d}$ & $P=0.12$ \\
\hline \multicolumn{4}{|l|}{ Year of vasectomy ${ }^{c}$} \\
\hline $1952-1969$ & $68(18.8)$ & $68(20.0)$ & $0.9(0.6-1.2)$ \\
\hline $1970-1974$ & $68(18.8)$ & $80(23.5)$ & $0.8(0.6-1.1)$ \\
\hline $1975-1979$ & $68(18.8)$ & $59(17.4)$ & $1.1(0.7-1.6)$ \\
\hline $1980-1989$ & $46(12.7)$ & $38(11.2)$ & $1.1(0.7-1.8)$ \\
\hline \multirow[t]{2}{*}{$1990-2003$} & $111(30.7)$ & $95(27.9)$ & $1.2(0.9-1.7)$ \\
\hline & & trend test ${ }^{d}$ & $P=0.11$ \\
\hline
\end{tabular}

${ }^{a}$ Adjusted for age, race, first-degree family history of prostate cancer, and screening history of PSA/DRE on the past 5 years.

${ }^{b}$ Reference group for all ORs related to vasectomy.

${ }^{c}$ Variable numbers of cases and controls reflect instances of unknown data for age and date of vasectomy.

$d_{\text {Trend test base on exposed subjects only. }}$ 